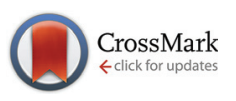

Cite this: Food Funct., 2016, 7, 2185

\section{Rosemary extracts in functional foods: extraction, chemical characterization and incorporation of free and microencapsulated forms in cottage cheese}

\author{
Andreia Ribeiro, ${ }^{\mathrm{a}, \mathrm{b}}$ Cristina Caleja, ${ }^{\mathrm{a}, \mathrm{b}}$ Lillian Barros, ${ }^{\mathrm{a}}$ Celestino Santos-Buelga, ${ }^{\mathrm{c}}$ \\ Maria Filomena Barreiro*b and Isabel C. F. R. Ferreira*a
}

\begin{abstract}
Consumers search for food with functional characteristics beyond its nutritional properties. Thus, the concept of functional food has become a hot topic, allowing us to obtain additional health benefits, including disease prevention. In this context, plants are recognized as sources of a wide range of bioactives, including phenolic compounds. Herein, rosemary aqueous extract was used as a functional ingredient for cottage cheese, after proving that it possesses both higher content of phenolic compounds and antioxidant activity, comparatively with the corresponding hydroethanolic extract. However, a decrease of bioactivity was observed for the cheese samples enriched with the extracts in free form after seven days under storage. Therefore, in order to preserve the antioxidant activity, the rosemary aqueous extract was efficiently microencapsulated by using an atomization/coagulation technique. Overall, the introduction of both free and microencapsulated extracts provided bioactivity that was better preserved with microencapsulated extracts without changing the nutritional value of cottage cheese.
\end{abstract}

Received 29th February 2016, Accepted 8th April 2016

DOI: $10.1039 / \mathrm{c} 6$ fo00270f

www.rsc.org/foodfunction as well as during storage and food processing, can degrade leading to a consequent loss of bioactivity. ${ }^{9}$ Moreover, after ingestion, they are metabolized into glucuronated, sulphated and methylated metabolites that can become bioinactive. ${ }^{10}$

To overcome these problems, the microencapsulation technique (defined as a technology of entrapping solids, liquids or gaseous materials in small capsules or spheres) has been used. ${ }^{11}$ Microencapsulation can provide a physical barrier between the core material, a matrix enriched in the bioactive compounds or the bioactive compounds themselves, and components of the surrounding medium. ${ }^{12}$ This methodology helps, not only to protect functional compounds, such as polyphenols and other antioxidants, but is also capable of providing controlled release, or a target delivery to a specific site. $^{12}$

The alginate, usually commercialized in the form of a sodium salt, is a polyanionic copolymer formed by $\alpha$-L-guluronic acid and $\beta$-D-mannuronic acid units. It is derived from marine kelp, mainly the brown sea algae ${ }^{13}$ and has been extensively investigated due to its biocompatibility, low toxicity, relatively low cost, and mild gelation by addition of divalent cations such as $\mathrm{Ca}^{2+} \cdot{ }^{14}$ This polymer has received great attention since its behaviour varies with the $\mathrm{pH}$, namely, it resists acidic media and solubilizes at basic $\mathrm{pH}^{15}$ The alginate was already reported as a suitable coating material to protect 
bioactive natural extracts by microencapsulation, aiming at their incorporation in foods. ${ }^{16,17}$

Stojanovic et al. ${ }^{18}$ studied the alginate encapsulation of aqueous thyme extracts also rich in rosmarinic acid and many polyphenolic compounds similar to rosemary extract; the authors reported the potential of using a hydrogel material for encapsulation of natural compounds to improve their functionality and stability in food products. Another formulation with alginate and rosemary are coating films to inhibit lipid oxidation and the warmed-over flavor formation (WOF) in pre-cooked meats. Handley et al. ${ }^{19}$ and Ma-Edmonds et al. ${ }^{20}$ added rosemary oleoresin extract (antioxidant activity) into starch-alginate coatings with the aim of protecting precooked pork chops and beef patties, respectively, from being oxidised.

However, microencapsulation with this polymer can increase the half-life of the extracts and allows the delivery of the bioactive compounds at the intestinal tract, which constitutes an advantage in terms of preserving their bioavailability.

In this work, two different rosemary extracts (aqueous and hydroethanolic) were prepared, then chemically characterized and evaluated for their radical-scavenging activity, reducing power and lipid peroxidation inhibition. The extract with the highest antioxidant activity (aqueous extract) was chosen to functionalize a dairy product (cottage cheese), firstly tested directly in free form and thereafter microencapsulated by an atomization/coagulation technique with calcium alginate as the coating material. As a final step of this work, the produced microspheres were incorporated into cottage cheese and the properties of the final product were evaluated and compared with the counterparts using extracts in free form, as well as with a control sample (cheese without extracts).

\section{Materials and methods}

\subsection{Plant species and preparation of the extracts}

Samples of dried Rosmarinus officinalis L. leaves (rosemary) were provided by "Cantinho das Aromáticas" organic farmers from Vila Nova de Gaia (Portugal). The dried leaves were crushed with a mortar to obtain a fine powder.

The hydroethanolic extracts were prepared by stirring the sample ( $2 \mathrm{~g}$ ) with $30 \mathrm{~mL}$ of ethanol : water $(80: 20, \mathrm{v} / \mathrm{v})$ at room temperature for $1 \mathrm{~h}$, followed by filtration through a Whatman filter paper no. 4. The residue was extracted again under the same conditions and mixed with the previously obtained extract. Ethanol was removed by evaporation under reduced pressure (Büchi R-210, Flawil, Switzerland) and the water was eliminated by lyophilisation (FreeZone 4.5, Labconco, Kansas City, MO, USA).

The aqueous extracts were obtained by adding $100 \mathrm{~mL}$ of boiling distilled water to the sample $(2 \mathrm{~g})$ followed by gentle stirring for seven minutes (infusion preparation), and filtration through a Whatman filter paper no. 4. Finally the extract was frozen and lyophilized.

\subsection{Standards and reagents}

For antioxidant tests, 2,2-dipheny-1-picrylhydrazyl (DPPH) was obtained from Alfa Aesar (Ward Hill, MA, USA). For chromatographic analysis, HPLC-grade acetonitrile was from Fisher Scientific (Lisbon, Portugal). The standards, such as fatty acids methyl ester (FAME) reference standard mixture (standard 47885-U), $\beta$-carotene and Trolox (6-hydroxy-2,5,7,8-tetramethylchroman-2-carboxylic acid) were purchased from sigma (St Louis, MO, USA), as also formic acid. Phenolic compound standards, namely rosmarinic and caffeic acids, were purchased from Extrasynthèse (Genay, France). Sodium alginate was provided from Fluka Chemie (Steinheim, Switzerland). All other chemicals and solvents were of analytical grade and purchased from common sources. Water was treated in a Milli-Q water purification system (TGI Pure Water Systems, Greenville, SC, USA).

\subsection{Chemical characterization of the rosemary extracts in terms of phenolic compounds}

Phenolic compounds were analysed using a Hewlett-Packard 1100 chromatograph (Hewlett-Packard 1100, Agilent Technologies, Santa Clara, CA, USA) with a quaternary pump and a diode array detector (DAD) coupled to an HP Chem Station (rev. A.05.04) for data-processing. A Waters Spherisorb S3 ODS-2 $\mathrm{C}_{18}, 3 \mu \mathrm{m}(4.6 \mathrm{~mm} \times 150 \mathrm{~mm})$ column thermostatted at $35{ }^{\circ} \mathrm{C}$ was used. The solvents used were: (A) $0.1 \%$ formic acid in water, and (B) acetonitrile. The elution gradient established was isocratic $15 \%$ for $5 \mathrm{~min}, 15 \% \mathrm{~B}$ to $20 \% \mathrm{~B}$ over $5 \mathrm{~min}$, $20-25 \%$ B over $10 \mathrm{~min}, 25-35 \%$ B over $10 \mathrm{~min}$ and $35-50 \% \mathrm{~B}$ for $10 \mathrm{~min}$, and re-equilibration of the column was performed using a flow rate of $0.5 \mathrm{~mL} \mathrm{~min}^{-1}$. Double online detection was carried out in the DAD using 280,330 and $370 \mathrm{~nm}$ as preferred wavelengths and in a mass spectrometer (MS) connected to the HPLC system via the DAD cell outlet. ${ }^{21,22}$

MS detection was performed in an API 3200 Qtrap (Applied Biosystems, Darmstadt, Germany) equipped with an ESI source and a triple quadrupole-ion trap mass analyzer that was controlled by Analyst 5.1 software. Zero grade air served as the nebulizer gas (30 psi) and turbo gas for solvent drying $\left(400{ }^{\circ} \mathrm{C}\right.$, 40 psi). Nitrogen served as the curtain (20 psi) and collision gas (medium). The quadrupoles were set at unit resolution. The ion spray voltage was set at $-4500 \mathrm{~V}$ in the negative mode. The MS detector was programmed for recording in two consecutive modes: Enhanced MS (EMS) and enhanced product ion (EPI) analysis. EMS was employed to show full scan spectra, so as to obtain an overview of all of the ions in the sample. Settings used were: declustering potential (DP) $-450 \mathrm{~V}$, entrance potential (EP) $-6 \mathrm{~V}$, collision energy (CE) -10 V. The EPI mode was performed in order to obtain the fragmentation pattern of the parent ion(s) in the previous scan using the following parameters: DP $-50 \mathrm{~V}, \mathrm{EP}-6 \mathrm{~V}, \mathrm{CE}-25 \mathrm{~V}$, and collision energy spread (CES), $0 \mathrm{~V}$. Spectra were recorded in negative ion mode between $\mathrm{m} / \mathrm{z} 100$ and 1500 .

The phenolic compounds were identified by comparing their retention times, UV-vis and mass spectra with those 
obtained with standard compounds, when available. Otherwise, compounds were tentatively identified comparing the obtained information with the available data reported in the literature. For quantitative analysis, a calibration curve for each available phenolic standard was constructed based on the UV signal. For the identified phenolic compounds for which a commercial standard was not available, the quantification was performed through the calibration curve of another compound from the same phenolic group. The results were expressed as mg per $\mathrm{g}$ of extract. ${ }^{22}$

\subsection{Evaluation of the antioxidant activity of the rosemary extracts}

The hydroethanolic and aqueous extracts were dissolved in ethanol : water $(80: 20, \mathrm{v} / \mathrm{v})$ and water, respectively, at a concentration of $10 \mathrm{mg} \mathrm{mL}^{-1}$, and further diluted to different concentrations until $2.4 \mu \mathrm{g} \mathrm{mL} \mathrm{mL}^{-1}$ in order to determine the $\mathrm{EC}_{50}$ values (extract concentration providing 50\% of antioxidant activity or an absorbance value of 0.5 in the reducing power assay). Trolox was used as positive control.

DPPH radical-scavenging activity, reducing power and lipid peroxidation inhibition were the in vitro assays used for the evaluation of the antioxidant activity and followed the experimental methodologies adopted in the work of Pereira et al. ${ }^{22}$ and Caleja et al. ${ }^{23}$ Briefly, DPPH radical scavenging activity was evaluated using an ELX800 microplate reader (Bio-Tek Instruments, Inc., Winooski, VT, USA), and calculated as a percentage of DPPH discoloration using the formula: $\left[\left(A_{\mathrm{DPPH}}-A_{\mathrm{S}}\right) /\right.$ $\left.A_{\mathrm{DPPH}}\right] \times 100$, where $A_{\mathrm{S}}$ is the absorbance of the solution containing the sample at $515 \mathrm{~nm}$, and $A_{\mathrm{DPPH}}$ is the absorbance of the DPPH solution. Reducing power was evaluated by the capacity to convert $\mathrm{Fe}^{3+}$ into $\mathrm{Fe}^{2+}$, by measuring the absorbance at $690 \mathrm{~nm}$ with the microplate reader mentioned above. Inhibition of lipid peroxidation using thiobarbituric acid reactive substances (TBARS) was evaluated by the lipid peroxidation inhibition in porcine brain homogenates where the colour intensity of the malondialdehyde-thiobarbituric acid (MDA-TBA) was measured by its absorbance at $532 \mathrm{~nm}$; the inhibition ratio (\%) is calculated using the following equation: $[(A-B) / A] \times 100 \%$, where $A$ and $B$ are the absorbance of the control and the sample solution, respectively. ${ }^{22}$

\subsection{Microencapsulation of rosemary aqueous extract and characterization}

2.5.1. Microencapsulation. The microspheres containing the rosemary aqueous extract were produced by using an atomization/coagulation technique, as previously described by the authors. ${ }^{16,17}$ In brief the encapsulating material (calcium alginate) was formed by using sodium alginate and a calcium chloride $\left(\mathrm{CaCl}_{2}\right)$ aqueous solution as the coagulation solution (source of $\mathrm{Ca}^{2+}$ ions). The atomization solution was prepared by firstly mixing $50 \mathrm{mg}$ of the rosemary extract with $10 \mathrm{~mL}$ water. This preparation was kept under stirring until complete dissolution of the extract; afterwards, $400 \mathrm{mg}$ of sodium alginate were added and the solution was kept under stirring for $2 \mathrm{~h}$ until complete dissolution. To produce the micro- spheres, a NISCO VarJ30 (Zurich, Switzerland) system was used, where the previously prepared alginate solution containing the aqueous extract was atomized using the following parameters: a feed rate of $0.2 \mathrm{~mL} \mathrm{~min}^{-1}$ and a nitrogen pressure of 100 mbar. The atomized droplets in contact with the $\mathrm{CaCl}_{2}$ solution $(250 \mathrm{~mL}$ at concentration of $4 \%(\mathrm{w} / \mathrm{v}))$ coagulate promptly fixing the microspheres' shape. For total consolidation they remained in contact with the coagulation solution for $4 \mathrm{~h}$ under stirring. Finally microspheres were recovered by filtration under reduced pressure, washed twice with water $(2 \times 100 \mathrm{~mL})$, lyophilized and stored.

2.5.2. Characterization. Optical microscopy (OM) (Nikon Eclipse 50i equipped with a Nikon Digital Sight, Tokyo, Japan) was used to monitor microspheres' morphology and size evolution during the microencapsulation process.

The encapsulation efficiency (EE) was evaluated by HPLC-DAD by quantifying the non-encapsulated rosmarinic acid (the major compound identified in the extract). For that the coagulation and the two washing solutions were analysed. The encapsulation efficiency was then calculated according to the following expression:

$$
\mathrm{EE}=\left[\left(M_{\mathrm{e}-\mathrm{t}}-M_{\mathrm{e}-\mathrm{ne}}\right) /\left(M_{\mathrm{e}-\mathrm{t}}\right)\right] \times 100
$$

where $M_{\mathrm{e}-\mathrm{t}}$ represents the theoretical amount of extract, i.e. the amount of extract used in the microencapsulation process, and $M_{\mathrm{e}-\mathrm{ne}}$ corresponds to the non-encapsulated extract. ${ }^{16}$

The presence of the extract inside the microcapsules was also confirmed by FTIR (Bomen, model MB 104) through the comparison of the spectra obtained with: (i) rosemary aqueous extract, (ii) alginate and (iii) microspheres. Spectra were obtained in transmittance mode by using the $\mathrm{KBr}$ pellet technique (concentration of $1 \%(\mathrm{w} / \mathrm{w})$ ) with a resolution of $4 \mathrm{~cm}^{-1}$ between 650 and $4000 \mathrm{~cm}^{-1}$ and by co-adding 48 scans.

\subsection{Functionalization of cottage cheese with rosemary aqueous extract}

2.6.1. Preparation of cottage cheese samples. All the cottage cheese samples were prepared, in duplicate, by Queijos Casa Matias Lda. (Seia, Portugal). Cottage cheeses are manufactured from the milk serum obtained after the production of cheese. Thus, for cheese production ewe milk (breed Churra Mondegueira), salt, and cardoon (Cynara cardunculus L.) were used, according to the procedure described by Carocho et al. ${ }^{24}$ Afterwards, the remaining serum (liquid component) was pumped into a vat where it was mixed and heated to a temperature ranging between $83-85^{\circ} \mathrm{C}$. After a few minutes at that temperature, the serum started to flocculate and rose to the surface where it was scooped into individual forms, left for a few minutes and packed with parchment paper. The incorporation of the bioactive extracts was carried out immediately before packaging individually into each one of the forms mentioned above, in order to guarantee a better distribution of the extract by the cottage cheese mass $(\sim 200 \mathrm{~g})$.

During the first stage of the work, control samples (cottage cheeses without rosemary extract) and cottage cheeses with rosemary extracts in free form $(0.1 \mathrm{~g}$ extract of cheese) were 
produced. During the second stage (after evaluating the behavior of the free extract) cottage cheeses with rosemary extracts in the microencapsulated form $(0.9 \mathrm{~g}$ microspheres of cheese corresponding to $0.1 \mathrm{~g}$ extract plus $0.8 \mathrm{~g}$ of alginate, the coating material) were prepared.

All the subsequent analyses were performed with the lyophilized cheese samples obtained directly after incorporation (0 days) and after 7 days, packed with parchment paper and stored at $4{ }^{\circ} \mathrm{C}$ in a refrigerator.

2.6.2. Recovery evaluation of the cottage cheese samples. The accuracy was evaluated by the standard addition procedure (percentage of recovery), with three addition levels (50, 25 and $10 \%$ of the peak/area concentration), each one in triplicate. The phenolic standards (rosmarinic acid and caffeic acid) were added to the samples and the extraction procedure was carried out. The lyophilized cheese samples ( $\left.\begin{array}{ll}1 & \mathrm{~g}\end{array}\right)$ were extracted with ethanol at room temperature for $1 \mathrm{~h}$ under stirring. The obtained extract was filtered through a Whatman filter paper no. 4 and the remaining solid residue was subjected to an additional extraction. The combined extracts were evaporated under reduced pressure in a rotatory evaporator until complete removal of ethanol. The extracts were evaluated using the HPLC system described above for the phenolic compounds (methodologies described in section 2.4).

2.6.3. Evaluation of the antioxidant activity of the cottage cheese samples. The lyophilized cheese samples (3 g) were extracted with ethanol at room temperature for $1 \mathrm{~h}$ under stirring. The obtained extract was filtered through a Whatman filter paper no. 4 and the remaining solid residue was subjected to an additional extraction. The combined extracts were evaporated under reduced pressure in a rotatory evaporator until complete removal of ethanol. Finally, the evaporated extract was dissolved in ethanol at a concentration of $200 \mathrm{mg} \mathrm{mL}$ for the antioxidant activity evaluation.

The antioxidant activity was evaluated though the DPPH radical scavenging activity and reducing power assays (methodologies described above in section 2.4).

2.6.4. Evaluation of the nutritional and colour properties of the cottage cheese samples. The nutritional composition (protein, fat, carbohydrates and ash) was evaluated using the AOAC procedures: ${ }^{25}$ the protein content $(\mathrm{N} \times 6.38)$ was determined using the Kjeldahl method; the fat content was determined by Soxhlet extraction with petroleum ether; the ash content was determined by incineration at $600 \pm 15{ }^{\circ} \mathrm{C}$; and total carbohydrates were calculated by difference. Total energy was calculated as Energy $(\mathrm{kcal})=4 \times($ protein weight $(\mathrm{g})+$ carbohydrate weight $(\mathrm{g}))+9 \times($ lipid weight $(\mathrm{g}))$.

Fatty acids were determined by analysing the petroleum ether extract previously obtained by gas-chromatography coupled with a flame ionization detector (GC-FID), according to the procedure described by the authors. ${ }^{22,23}$ The identification was made by comparison of the relative retention times of fatty acid methyl esters with standards. The results were expressed as relative percentages.

Free sugars were determined in defatted samples by HPLC coupled to a refractive index (RI) detector, according to the procedure previously described by the authors. ${ }^{21,22}$ The compounds were identified by chromatographic comparisons with authentic standards, and quantification was performed using the internal standard (melezitose) method. The sugar content was expressed in $\mathrm{g}$ per $100 \mathrm{~g}$ of the cottage cheese. ${ }^{22,23}$

Sample colour was determined in a colorimeter (model CR-400, Konica Minolta Sensing, Inc., Japan) using the illuminant $\mathrm{C}$ and a diaphragm aperture of $8 \mathrm{~mm}$. The CIE $L^{*} a^{*} b^{*}$ colour space values were registered using the data software "Spectra Magic Nx" (version CM-S100W 2.03.0006). ${ }^{23}$ Three readings on the sample top and bottom parts were used.

\subsection{Statistical analysis}

All the assays (antioxidant activity, nutritional and colour properties) were carried out in triplicate and the results expressed as mean values with the corresponding standard deviation (SD). The results were analyzed using one-way analysis of variance (ANOVA) followed by Tukey's HSD test with $\alpha=0.05$. In the case of antioxidant activity, Student's $t$-test was used to determine the significant difference among the different samples, with $\alpha=0.05$. This treatment was carried out using SPSS V22.0 program.

\section{Results and discussion}

\subsection{Chemical characterization of the rosemary extracts in terms of phenolic compounds}

Water and a mixture of ethanol: water were selected for the preparation of the extracts, for being considered suitable for phenolic compound extraction, as well as "green" solvents with no or very low toxicity. Therefore, the extracts may become suitable for incorporation in food matrices.

Fig. 1 shows the phenolic compound profile, recorded at $280 \mathrm{~nm}$, of a Rosmarinus officinalis (rosemary) aqueous extract, prepared by infusion. Data of retention time, $\lambda_{\max }$, pseudomolecular ion, main fragment ions in $\mathrm{MS}^{2}$, and tentative compound identification are presented in Table 1.

The phenolic composition of the extracts was characterized by the presence of caffeoyl derivatives, which constituted 16 out of the 18 detected phenolic compounds, as revealed by the observation in their mass spectra of signals at $\mathrm{m} / \mathrm{z} 179,161$ and/or 135 characteristic of caffeic acid. The other two compounds (i.e., peaks 8 and 14) corresponded to flavonoids.

Caffeic acid (compound 4) and rosmarinic acid (compound 12) were positively identified according to their retention, mass spectra and UV-vis characteristics in comparison with commercial standards. The presence of caffeic and rosmarinic acids has been extensively reported in rosemary. ${ }^{26-30}$ Based on their mass spectra, compounds 1 and $2\left([\mathrm{M}-\mathrm{H}]^{-}\right.$at $\left.m / z 341\right)$, and $7\left([\mathrm{M}-\mathrm{H}]^{-}\right.$at $\left.m / z 521\right)$ were identified as hexoside derivatives of caffeic and rosmarinic acids, respectively. Both types of compounds have been previously described to be present in rosemary. ${ }^{28,29}$ Compound 3, with an $\mathrm{MS}^{2}$ base peak at $m / z 173$ [quinic acid $-\mathrm{H}-\mathrm{H}_{2} \mathrm{O}$ ] and a prominent secondary fragment ion at $m / z 179$ [caffeic acid - H], was identified as 4-O-caffeoyl- 


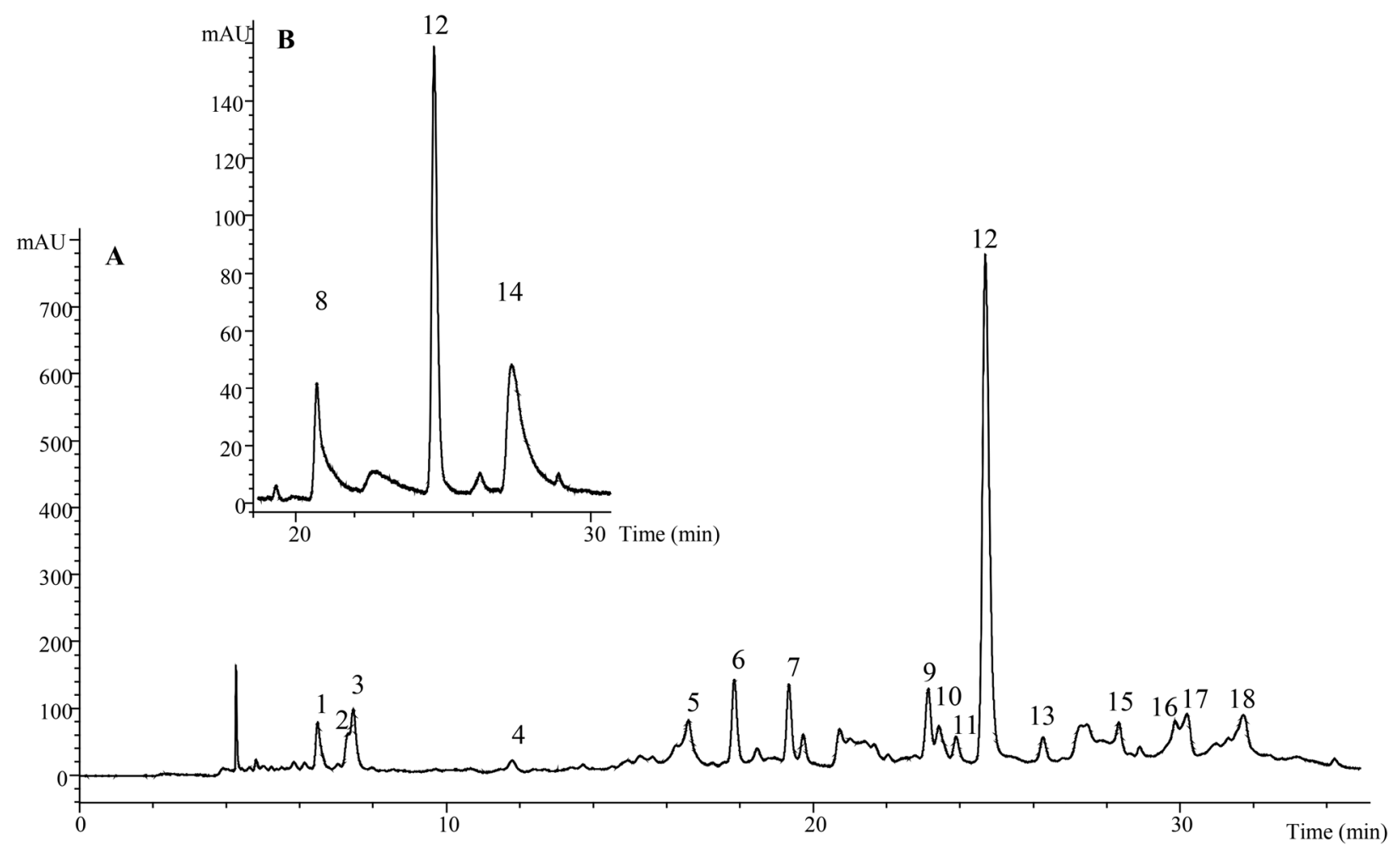

Fig. 1 HPLC phenolic profile of Rosmarinus officinalis infusions obtained at $280 \mathrm{~nm}$ (A) and $370 \mathrm{~nm}$ (B).

quinic acid based on the hierarchical keys described by Clifford et al. $^{31}$ for the fragmentation patterns of chlorogenic acids.

Peaks 5, 6, 11, 15 and 17 were identified as caffeic acid trimers, and peaks 10 and 16 as caffeic acid tetramers according to their UV and mass characteristics and comparison with literature data. ${ }^{32-34}$

Compounds $5\left([\mathrm{M}-\mathrm{H}]^{-}\right.$at $\left.m / z 539\right)$ and $6\left([\mathrm{M}-\mathrm{H}]^{-}\right.$at $m / z$ 597) were identified as yunnaneic acid D and F, respectively, based on their UV and mass characteristics as reported by Chen et al. $^{32}$ in aerial parts of Salvia miltiorrhiza. Similarly, compound $11\left([\mathrm{M}-\mathrm{H}]^{-}\right.$at $\left.m / z 535\right)$ was identified as sagecoumarin, a caffeic acid trimer described in S. miltiorrhiza. ${ }^{35,36}$ Compounds 15 and 17 presented the same pseudomolecular ion $[\mathrm{M}-\mathrm{H}]^{-}$at $m / z 537$, the UV spectrum and fragmentation pattern consistent with the caffeic acid trimer lithospermic acid A. This compound can easily lose the 8 "-carboxyl group (-44 mu) releasing a fragment at $m / z 493$ that further breaks down to form the fragment ions at $m / z 313$ and 295. Salvianolic acids $\mathrm{H} / \mathrm{I}$, with the same molecular weight as lithospermic acid A, were discarded as possible identities because they present quite a different fragmentation pattern. ${ }^{33}$

Compound 10 showed a pseudomolecular ion $[\mathrm{M}-\mathrm{H}]^{-}$at $m / z 719$ and an $\mathrm{MS}^{2}$ majority fragment at $\mathrm{m} / \mathrm{z} 359$ corresponding to $[\mathrm{M}-2 \mathrm{H}]^{2-}$; these mass characteristics coincided with those of sagerinic acid, a rosmarinic acid dimer reported in other Lamiaceae like Salvia ${ }^{35}$ or Melissa officinalis. ${ }^{34}$ Compound $16\left([\mathrm{M}-\mathrm{H}]^{-}\right.$at $\left.m / z 717\right)$ presented a fragmentation pattern with successive losses of $198 \mathrm{mu}$ (danshensu) or $180 \mathrm{mu}$ (caffeic acid) units, coherent with salvianolic acid B (also known as lithospermic acid B), largely found in Salvia species. ${ }^{33,36-38}$ A compound with the same pseudomolecular ion was reported in rosemary by Borrás-Linares et al. ${ }^{26}$ without offering any identity, and also by Ferrer-Gallego et al. ${ }^{29}$ that was identified as just salvianolic acid. Compounds $9\left([\mathrm{M}-\mathrm{H}]^{-}\right.$ at $m / z 777)$ and $18\left([\mathrm{M}-\mathrm{H}]^{-}\right.$at $\left.m / z 727\right)$ should also correspond to caffeic acid tetramers taking into account their molecular weights and fragmentation patterns, although no definite identity could be assigned to them. In the case of compound 9 the fragments observed at $\mathrm{m} / \mathrm{z} 535$ and 491 would fit, respectively, the caffeic acid trimers sagecoumarin and salvianolic acid C, whereas fragments at $\mathrm{m} / \mathrm{z} 311$ and 293 have been cited to be produced by the latter compound, ${ }^{33,37}$ suggesting that salvianolic acid $\mathrm{C}$ could be a part of the structure of compound 9. Similarly, compound 18 presented a similar fragmentation pattern as compound 16 (salvianolic acid B), indicating that both of them share common structural features, although no structure could be matched to its molecular weight. No identity could be assigned to compound $\mathbf{1 3}$ $\left([\mathrm{M}-\mathrm{H}]^{-}\right.$at $\left.m / z 487\right)$ either, although it would also correspond to a caffeic acid derivative as revealed by the characteristic fragment ions at $m / z 179,161$ and 135.

To the best of our knowledge, most of the above discussed caffeic acid trimers and tetramers are described for rosemary for the first time in the present study, since only the presence of two salvianolic acid derivatives has been reported by Ferrer- 
Table 1 Retention time (Rt), wavelengths of maximum absorption in the visible region $\left(\lambda_{\text {max }}\right)$, mass spectral data, identification and quantification of phenolic compounds in rosemary extracts

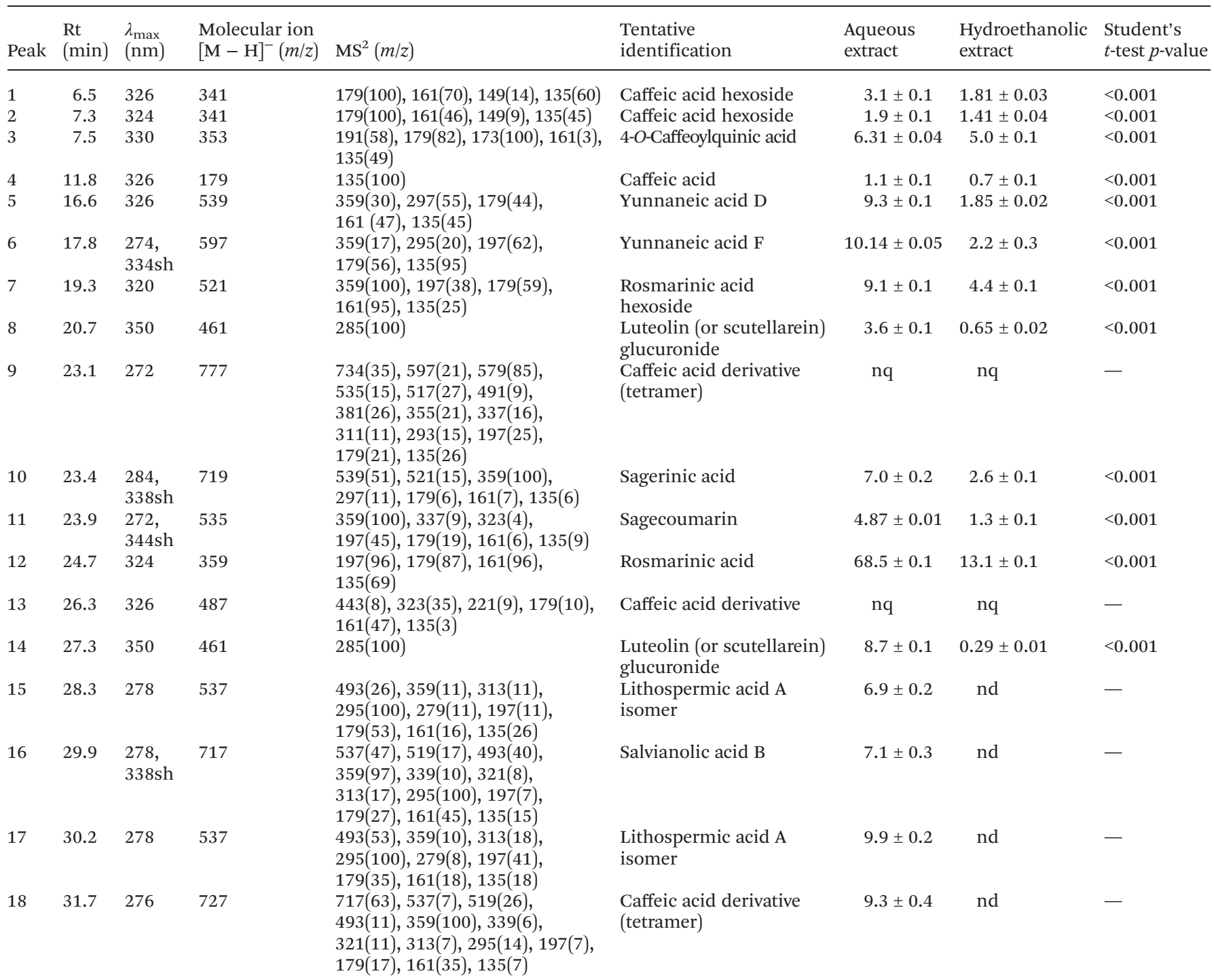

nq - not quantified; nd - not detected.

Gallego et al. ${ }^{29}$ without however offering a complete identification for them. The quantification of all these derivatives was made based on the calibration curves of caffeic and rosmarinic acids.

Finally, peaks 8 and 14, the only flavonoids found in this sample, were identified as flavone derivatives. Both compounds presented UV spectra with $\lambda_{\max }$ at $350 \mathrm{~nm}$, and the same pseudomolecular ion $[\mathrm{M}-\mathrm{H}]^{-}$at $m / z 461$, releasing a unique $\mathrm{MS}^{2}$ fragment at $\mathrm{m} / \mathrm{z} 285\left([\mathrm{M}-\mathrm{H}-176]^{-}\right.$, loss of a glucuronyl moiety). Different luteolin and scutellarein glucuronides that may match these characteristics have been reported in rosemary leaves, namely luteolin-7-O-glucuronide, ${ }^{26,27}$ luteolin-3-O-glucuronide, ${ }^{29}$ luteolin-3'-O-glucuronide ${ }^{28}$ and scutellarein-7-O-glucuronide. ${ }^{26}$ The presence of homoplantaginin (i.e., hispidulin-7-O-glucoside) with the same molecular weight has also been cited in rosemary, ${ }^{27,28}$ although such an identity should be discarded in our case since the fragment corresponding to the aglycone (hispidulin, $M_{\mathrm{w}} 300 \mathrm{Da}$ ) was not observed in the $\mathrm{MS}^{2}$ spectra of the compounds. No conclusions about the location of the glucuronide moiety can be drawn from the HPLC-DAD-MS data obtained herein, therefore the compounds were just assigned as luteolin (or scutellarein) glucuronide.

The diterpene carnosic acid and its related compounds, carnosol, methyl carnosate, or other derivatives were not present in the studied sample, neither in the aqueous nor in the ethanol extracts. The aqueous extract presented the highest content in total and individual phenolic compounds, with rosmarinic acid being the most abundant compound in both samples (Table 1). 


\subsection{Antioxidant properties of the rosemary extracts}

The two prepared rosemary extracts (aqueous and hydroethanolic) revealed the same tendency regarding their antioxidant capacity in the three evaluation assays: lipid peroxidation inhibition $>$ reducing power $>$ DPPH scavenging activity (Fig. 2), however, the aqueous extract always showed lower $\mathrm{EC}_{50}$ values (higher antioxidant activity) than the hydroethanolic one. Therefore, the aqueous extract was selected to functionalize the cottage cheese, in order to provide antioxidant benefits to this food matrix.

\subsection{Incorporation of the aqueous extract in cottage cheese}

The accuracy of the incorporation was evaluated by the standard addition procedure (percentage of recovery). Rosmarinic and caffeic acids were added to the control samples, to the samples with rosemary aqueous extracts in free form and to the samples with microcapsules. The recovery was performed using three concentration levels $(10,25$ and $50 \%$ of the peak/ area concentration, each one in triplicate) before the extraction procedure. Recovery values showed excellent results for the samples with rosemary aqueous extracts incorporated in free form, with a mean percentage of 95\%, while control and microencapsulated samples did not present any of these compounds.

The effect of rosemary extract on the antioxidant activity of the cottage cheese samples was firstly evaluated using the extract in free form and compared with the control (sample

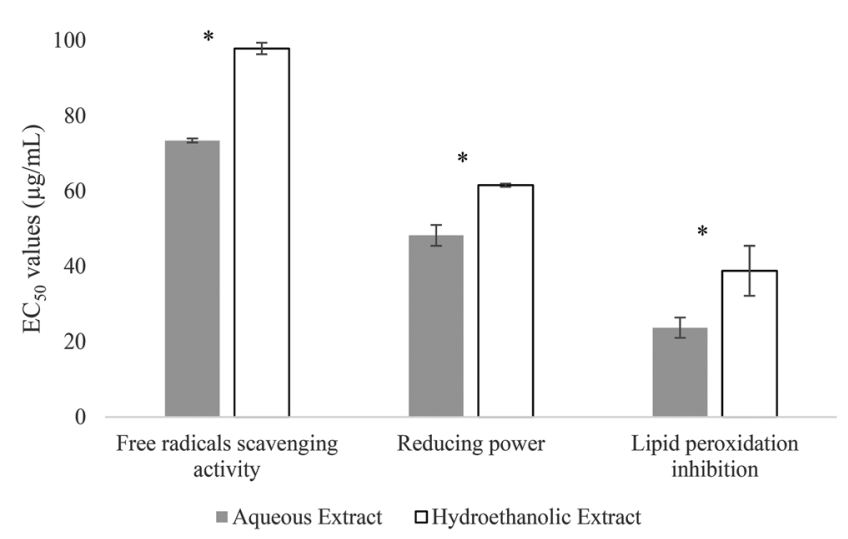

Fig. 2 Antioxidant activity ( $\mathrm{EC}_{50}$ values, $\mu \mathrm{g} \mathrm{mL}^{-1}$ ) of the aqueous and hydroethanolic rosemary extracts (mean values $\pm S D$ ). Error bars represent standard deviations (SD). ${ }^{*} P<0.001$, results that are significantly different. with no extract added). Antioxidant activity (free radicals scavenging activity and reducing power assays), was determined directly after incorporation (0 days) and after storage for 7 days at $4{ }^{\circ} \mathrm{C}$. The control samples did not show any free radical scavenging activity (Table 2), however, low reducing power was observed that improved along time, which is probably related to the formation of reducing substances in the cottage cheese after the lipid peroxidation process. In comparison, the incorporation of the rosemary aqueous extracts in free form improved the antioxidant activity of the cottage cheese for both studied times ( 0 and 7 days). Nevertheless, a reduction in the antioxidant potential of these samples was observed along the storage time, indicating a loss of bioactivity of the extract, probably related to its degradation. Therefore, microencapsulation was attempted to provide protection against the degradation of the used rosemary extract.

\subsection{Microencapsulation of the rosemary aqueous extract with alginate by atomization/coagulation process}

Alginate-based microspheres containing the rosemary aqueous extract were prepared by the atomization/coagulation technique. The used conditions were adapted from similar work carried out with other natural extracts. ${ }^{16,17}$ The produced microspheres were analyzed by OM, immediately after the atomization process (Fig. 3A1) and after the coagulation period ( $4 \mathrm{~h}$ under stirring in a solution of $\mathrm{CaCl}_{2}$ ) (Fig. 3A2). In both stages, it was observed that the produced microspheres presented, in general, a round and well defined shape; only a minor proportion, particularly the microspheres with low size, revealed a pear-like form. Moreover they were perfectly individualized (no agglomerates were detected). The presence of small brown droplets was also noticed and related to the presence of the extract (effective incorporation of the extract inside the alginate microspheres).

Their final size (estimated by OM using a magnification of $100 \times$ ) ranged between 51.1 and $122.6 \mu \mathrm{m}$. The encapsulation efficiency (EE), evaluated through an indirect method based on the quantification of the non-encapsulated rosmarinic acid by HPLC-DAD, was determined as $100 \%$ (no compound was detected in the analysed coagulation and washing solutions).

The lyophilized microparticles were analyzed by OM. As can be observed in Fig. 3A3, the microspheres maintained a shape similar to the one observed previously for the hydrated microspheres obtained after the encapsulation process (round and pear-type form), although they showed a roughened surface due to water removal, a consequence of the drying process.

Table 2 Antioxidant activity of the control and cottage cheeses (CC) with free aqueous extract, along storage (mean values \pm SD)

\begin{tabular}{|c|c|c|c|c|c|c|}
\hline $\mathrm{EC}_{50}$ values $\left(\mathrm{mg} \mathrm{mL}^{-1}\right)$ & Control & $\begin{array}{l}\text { CC with free } \\
\text { extract }\end{array}$ & $\begin{array}{l}\text { Student's } t \text {-test } \\
p \text {-value }\end{array}$ & Control & $\begin{array}{l}\text { CC with free } \\
\text { extract }\end{array}$ & $\begin{array}{l}\text { Student's } t \text {-test } \\
p \text {-value }\end{array}$ \\
\hline DPPH scavenging activity & $>200$ & $13.24 \pm 0.15$ & $<0.001$ & $>200$ & $17.07 \pm 0.38$ & $<0.001$ \\
\hline Reducing power & $40.02 \pm 0.18$ & $8.10 \pm 0.05$ & $<0.001$ & $15.78 \pm 0.67$ & $11.13 \pm 0.05$ & $<0.001$ \\
\hline
\end{tabular}



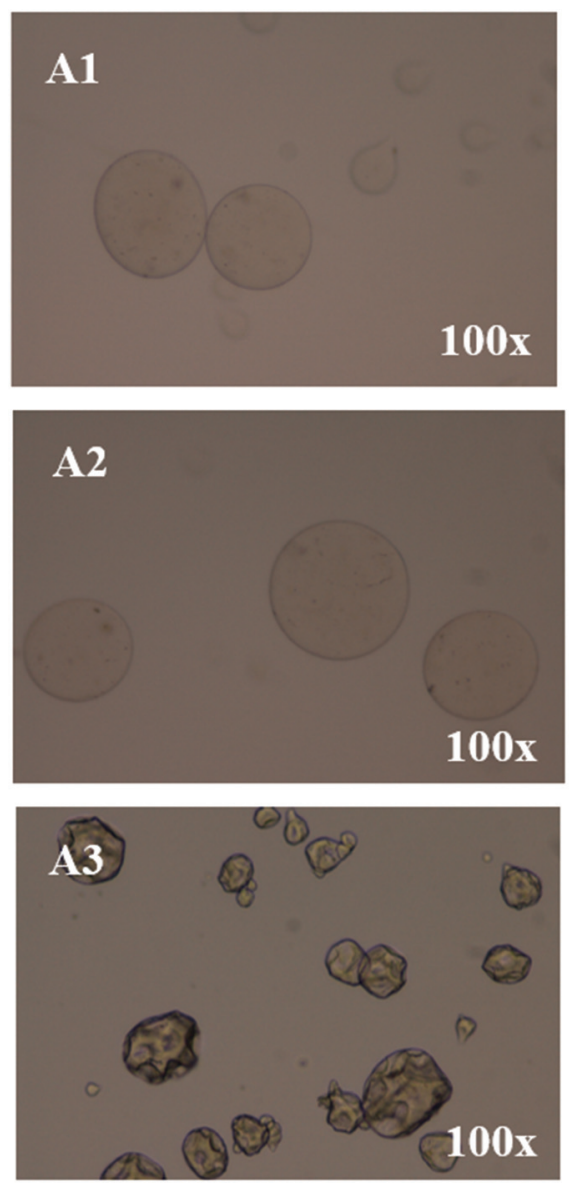

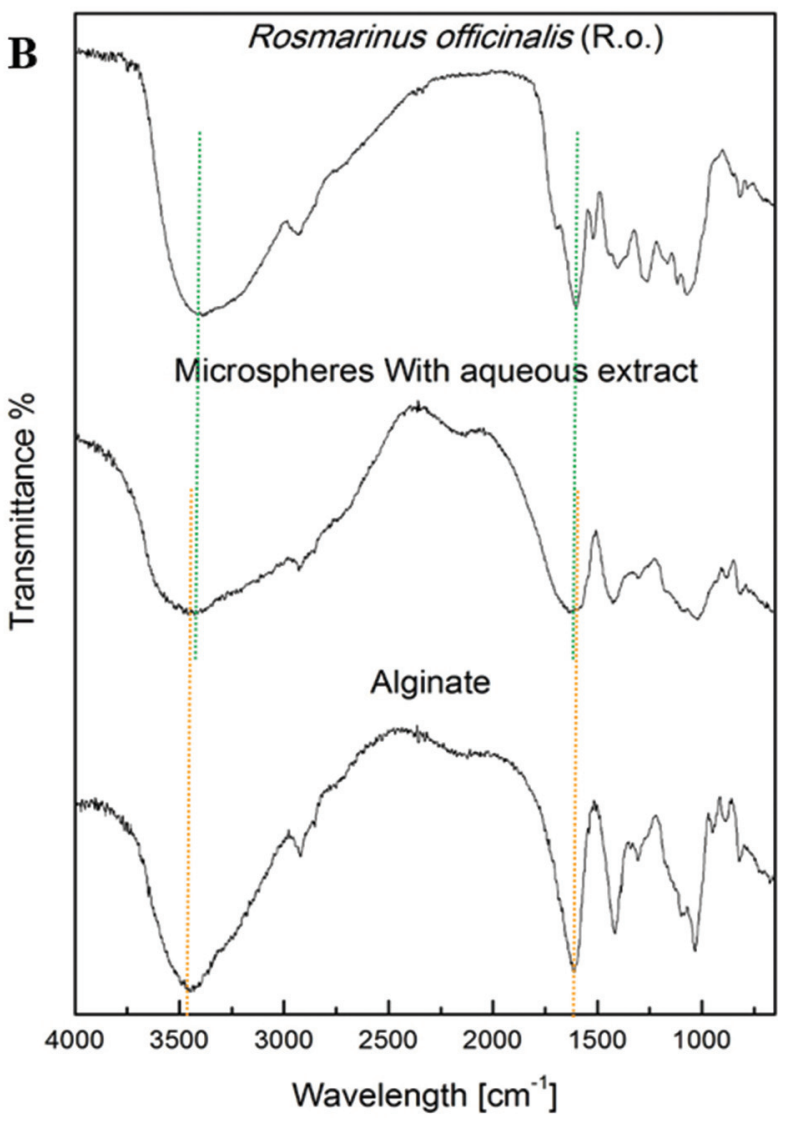

Fig. 3 A. OM analysis with magnifications of $100 x$. A1 - microspheres after atomization; $\mathrm{A} 2-$ microspheres after $4 \mathrm{~h}$ in contact with $\mathrm{CaCl}_{2}$ solution under stirring at $200 \mathrm{rpm}$; A3 - freeze-dried microspheres. B. FTIR analysis of the rosemary aqueous extract, microspheres with rosemary extract and pure alginate.

The FTIR spectra of the lyophilized aqueous extract, microspheres and alginate are shown in Fig. 3B. The microspheres spectrum, as expected, is dominated by the presence of alginate (orange dotted lines). The ratio of extract/alginate was 50/400, which explains the alginate preponderance. Nevertheless, a contribution from both carbonyl $(\mathrm{C}=\mathrm{O})$ and hydroxyl $(\mathrm{OH})$ groups of the extract (green dotted lines) was observed. Also a widening of the $\mathrm{OH}$ and $\mathrm{C}=\mathrm{O}$ bands can be observed. These observations represent evidence of an effective extract encapsulation.

\subsection{Incorporation of the microencapsulated aqueous extract in cottage cheese}

Following the results obtained with the incorporation of the rosemary extract in free form, where a loss of bioactivity was observed after 7 days, and after the successful application of the microencapsulation process, the extract in the microencapsulated form was used to functionalize the cheese samples. The obtained results showed no antioxidant activity for both assayed times ( $t_{0} /$ initial time and $t_{7} /$ after 7 days of storage), demonstrating the effective protection of the extract inside the microspheres. To prove the existence of a viable extract inside the microspheres, even after 7 days, a cheese added with extract in the microencapsulated form was subjected to an ultrasound extraction $(75 \%, 30 \mathrm{~min})$. The results showed antioxidant activity $\left(\mathrm{EC}_{50}\right.$ value $\left.=103.08 \pm 6.61 \mathrm{mg} \mathrm{mL}{ }^{-1}\right)$, which indicates the release of part of the extract as a consequence of the disruption of the alginate microspheres. Even though this test cannot be considered quantitative (the total delivery of the extract is not expected), it corroborates the presence of a viable extract inside the microspheres, and thus the advantage of using the microencapsulation as an effective tool to incorporate natural extracts in functional foods. It should also be highlighted that the coating material, alginate, has been recognized for its distinct features such as specific release under basic $\mathrm{pH},{ }^{39}$ allowing the protection of the phenolic bioactive compounds of the rosemary extract along the acidic $\mathrm{pH}$ of the stomach, and releasing them only in the intestinal tract where they will be absorbed.

\subsection{Colour and nutritional parameters of the control and cottage cheeses with free and microencapsulated aqueous rosemary extracts}

By incorporating new extracts/natural ingredients in well-established food products, it is very convenient and useful for the 
consumers and companies commercializing the products, to have knowledge about the effects of this incorporation in the nutritional and energetic contribution of the final product. Moreover, as polyphenols added to the cottage cheese could undergo severe browning reactions, the effects on colour and fatty acids are of particular importance.

Therefore, the colour and nutritional parameters were evaluated for all the cottage cheese samples before and after storage $\left(t_{0}\right.$ and $\left.t_{7}\right)$, and the results are shown in Table 3.

Colour is the first impression that a consumer gets about food quality, so the issue of visual perception is an important consideration in the development of new food products. The $L^{*}$ parameter indicates lightness, so higher values mean clearer objects; the $a^{*}$ value indicates the redness-greenness tendency, and the $b^{*}$ value indicates the blueness-yellowness tendency. At $t_{0}$ and $t_{7}$, the parameters $L^{*}$ and $b^{*}$ showed greater contribution to the total colour of the cottage cheeses, however, the $a^{*}$ value was close to zero and, therefore, its contribution to the total colour value was minimum. The $L^{*}$ parameter for the cottage cheeses ( 0 days) was not statistically different, however, after 7 days of storage there was a slight change.

Additionally, the cottage cheese samples were analyzed for their nutritional composition regarding ash, fat, protein and carbohydrate (including lactose) contents, as well as, total energy. The obtained results (Table 3 ) indicate that the nutritional properties of cottage cheese are maintained even after the incorporation of rosemary aqueous extracts (both in free and microencapsulated forms). Moisture decreased after storage, with a consequent increase in the fat and protein levels. As cottage cheese has relatively high levels of fat, individual fatty acid profiles were also analysed. As expected, saturated fatty acids, mainly myristic (C14:0), palmitic (C16:0) and stearic (C18:0) acids, constituted the main fatty acid fraction in the samples (Table 3).

Regarding carbohydrates, the control cottage cheese presented higher levels at $t_{0}$, whereas the samples with free and microencapsulated extract showed similar carbohydrate values, lower than the control cheese. At $t_{7}$, both control and cottage cheese with the microencapsulated extract presented similar

Table 3 Colour parameters and nutritional value of the control and cottage cheeses (CC) with free and microencapsulated aqueous extracts, along storage (mean values \pm SD)

\begin{tabular}{|c|c|c|c|c|c|c|}
\hline & \multicolumn{3}{|l|}{0 days } & \multicolumn{3}{|l|}{7 days } \\
\hline & Control & $\begin{array}{l}\text { CC with free } \\
\text { extract }\end{array}$ & $\begin{array}{l}\text { CC with } \\
\text { microencapsulated } \\
\text { extract }\end{array}$ & Control & $\begin{array}{l}\text { CC with free } \\
\text { extract }\end{array}$ & $\begin{array}{l}\mathrm{CC} \text { with } \\
\text { microencapsulated } \\
\text { extract }\end{array}$ \\
\hline \multicolumn{7}{|l|}{ Colour parameters } \\
\hline$L^{*}$ & $93.22 \pm 1.07^{\mathrm{a}}$ & $93.54 \pm 0.46^{\mathrm{a}}$ & $93.69 \pm 0.44^{\mathrm{a}}$ & $93.71 \pm 0.66^{\mathrm{a}}$ & $90.54 \pm 1.33^{\mathrm{c}}$ & $92.09 \pm 0.88^{\mathrm{b}}$ \\
\hline$a^{*}$ & $-2.50 \pm 0.18^{\mathrm{b}}$ & $-2.28 \pm 0.09^{\mathrm{a}}$ & $-2.49 \pm 0.10^{\mathrm{b}}$ & $-2.55 \pm 0.13^{b}$ & $-2.57 \pm 0.19^{b}$ & $-2.20 \pm 0.18^{\mathrm{a}}$ \\
\hline$b^{*}$ & $10.26 \pm 0.22^{\mathrm{a}}$ & $9.90 \pm 0.20^{\mathrm{a}}$ & $10.06 \pm 0.37^{\mathrm{a}}$ & $10.73 \pm 0.27^{\mathrm{a}}$ & $11.07 \pm 0.48^{\mathrm{a}}$ & $11.16 \pm 0.41^{\mathrm{a}}$ \\
\hline$C^{*}$ & $10.56 \pm 0.20^{\mathrm{a}}$ & $10.15 \pm 0.21^{\mathrm{a}}$ & $10.36 \pm 0.38^{\mathrm{a}}$ & $11.03 \pm 0.25^{\mathrm{a}}$ & $11.36 \pm 0.48^{\mathrm{a}}$ & $11.37 \pm 0.39^{\mathrm{a}}$ \\
\hline$h^{\circ}$ & $103.68 \pm 0.68^{\mathrm{ab}}$ & $102.95 \pm 0.42^{\mathrm{b}}$ & $103.91 \pm 0.31^{\mathrm{a}}$ & $103.39 \pm 0.89^{\mathrm{a}}$ & $103.10 \pm 0.92^{\mathrm{a}}$ & $101.16 \pm 1.15^{\mathrm{b}}$ \\
\hline \multicolumn{7}{|l|}{ Nutritional value } \\
\hline Moisture (g per $100 \mathrm{~g}$ fw) & $69.56 \pm 0.69^{b}$ & $71.94 \pm 1.70^{\mathrm{a}}$ & $69.51 \pm 0.53^{\mathrm{b}}$ & $62.67 \pm 1.17^{\mathrm{b}}$ & $64.53 \pm 1.26^{\mathrm{a}}$ & $62.44 \pm 1.81^{\mathrm{b}}$ \\
\hline Ash $(\mathrm{g}$ per $100 \mathrm{~g}$ fw) & $1.17 \pm 0.01^{b}$ & $1.11 \pm 0.07^{\mathrm{b}}$ & $1.34 \pm 0.06^{\mathrm{a}}$ & $1.22 \pm 0.05^{\mathrm{a}}$ & $1.00 \pm 0.01^{\mathrm{b}}$ & $1.30 \pm 0.04^{\mathrm{a}}$ \\
\hline Fat $(\mathrm{g}$ per $100 \mathrm{~g} \mathrm{fw})$ & $15.47 \pm 0.07^{\mathrm{a}}$ & $14.29 \pm 0.17^{\mathrm{b}}$ & $15.62 \pm 0.02^{\mathrm{a}}$ & $19.39 \pm 0.11^{\mathrm{a}}$ & $19.34 \pm 0.16^{\mathrm{a}}$ & $19.72 \pm 0.27^{\mathrm{a}}$ \\
\hline Protein ( $\mathrm{g}$ per $100 \mathrm{~g}$ fw) & $11.47 \pm 0.16^{\mathrm{a}}$ & $10.90 \pm 0.04^{\mathrm{b}}$ & $11.75 \pm 0.14^{\mathrm{a}}$ & $14.34 \pm 0.11^{\mathrm{a}}$ & $13.59 \pm 0.14^{\mathrm{b}}$ & $14.38 \pm 0.05^{\mathrm{a}}$ \\
\hline Carbohydrates (g per $100 \mathrm{~g}$ fw) & $2.33 \pm 0.10^{\mathrm{a}}$ & $1.76 \pm 0.20^{\mathrm{b}}$ & $1.77 \pm 0.15^{\mathrm{b}}$ & $2.38 \pm 0.20^{\mathrm{a}}$ & $1.54 \pm 0.19^{\mathrm{b}}$ & $2.15 \pm 0.27^{\mathrm{a}}$ \\
\hline Lactose (g per $100 \mathrm{~g}$ fw) & $1.93 \pm 0.04^{\mathrm{a}}$ & $1.76 \pm 0.01^{\mathrm{b}}$ & $1.78 \pm 0.03^{\mathrm{b}}$ & $1.80 \pm 0.07^{\mathrm{a}}$ & $0.63 \pm 0.01^{\mathrm{c}}$ & $0.75 \pm 0.03^{\mathrm{b}}$ \\
\hline Energy (kcal per $100 \mathrm{~g}$ fw) & $194.43 \pm 0.35^{\mathrm{a}}$ & $179.26 \pm 0.69^{\mathrm{b}}$ & $194.68 \pm 0.16^{\mathrm{a}}$ & $241.39 \pm 0.70^{\mathrm{a}}$ & $234.62 \pm 0.76^{b}$ & $243.63 \pm 1.18^{\mathrm{a}}$ \\
\hline \multicolumn{7}{|l|}{ Fatty acids } \\
\hline $\mathrm{C} 4: 0$ & $2.92 \pm 0.16^{c}$ & $3.61 \pm 0.17^{\mathrm{b}}$ & $3.96 \pm 0.01^{\mathrm{a}}$ & $3.87 \pm 0.27^{\mathrm{a}}$ & $2.15 \pm 0.21^{\mathrm{b}}$ & $3.73 \pm 0.06^{\mathrm{a}}$ \\
\hline C6:0 & $3.51 \pm 0.01^{\mathrm{b}}$ & $3.67 \pm 0.03^{\mathrm{a}}$ & $3.35 \pm 0.05^{c}$ & $3.76 \pm 0.03^{\mathrm{a}}$ & $3.11 \pm 0.22^{\mathrm{c}}$ & $3.59 \pm 0.01^{\mathrm{b}}$ \\
\hline C8:0 & $3.42 \pm 0.10^{\mathrm{a}}$ & $3.47 \pm 0.02^{\mathrm{a}}$ & $3.11 \pm 0.04^{\mathrm{b}}$ & $3.43 \pm 0.08^{\mathrm{a}}$ & $3.39 \pm 0.16^{\mathrm{a}}$ & $3.44 \pm 0.01^{\mathrm{a}}$ \\
\hline C10:0 & $8.44 \pm 0.22^{\mathrm{a}}$ & $8.42 \pm 0.18^{\mathrm{a}}$ & $7.91 \pm 0.22^{\mathrm{b}}$ & $8.18 \pm 0.31^{b}$ & $8.55 \pm 0.14^{\mathrm{a}}$ & $8.16 \pm 0.05^{b}$ \\
\hline C12:0 & $4.90 \pm 0.04^{\mathrm{a}}$ & $4.76 \pm 0.15^{\mathrm{a}}$ & $4.74 \pm 0.07^{\mathrm{a}}$ & $4.70 \pm 0.17^{\mathrm{b}}$ & $4.94 \pm 0.01^{\mathrm{a}}$ & $4.77 \pm 0.01^{\mathrm{ab}}$ \\
\hline C14:0 & $11.08 \pm 0.07^{\mathrm{a}}$ & $10.74 \pm 0.14^{\mathrm{b}}$ & $10.93 \pm 0.01^{\mathrm{a}}$ & $10.62 \pm 0.12^{c}$ & $11.04 \pm 0.08^{\mathrm{a}}$ & $10.83 \pm 0.05^{\mathrm{b}}$ \\
\hline C16:0 & $24.21 \pm 0.10 \mathrm{a}$ & $23.73 \pm 0.01^{c}$ & $24.03 \pm 0.14^{\mathrm{b}}$ & $23.64 \pm 0.08^{\mathrm{b}}$ & $24.20 \pm 0.18^{\mathrm{a}}$ & $23.74 \pm 0.05^{\mathrm{b}}$ \\
\hline C18:0 & $9.80 \pm 0.23 b$ & $12.38 \pm 1.76^{\mathrm{a}}$ & $11.11 \pm 0.30^{\mathrm{ab}}$ & $11.47 \pm 0.29^{\mathrm{ab}}$ & $13.18 \pm 1.86^{\mathrm{a}}$ & $10.70 \pm 0.10^{b}$ \\
\hline C18:1n9 & $23.56 \pm 0.37 a$ & $21.14 \pm 1.09^{\mathrm{b}}$ & $22.57 \pm 0.03^{\mathrm{ab}}$ & $22.23 \pm 0.46^{\mathrm{a}}$ & $20.94 \pm 1.18^{b}$ & $22.73 \pm 0.04^{\mathrm{a}}$ \\
\hline SFA (relative \%) & $70.64 \pm 0.42^{\mathrm{b}}$ & $73.11 \pm 1.06^{\mathrm{a}}$ & $71.55 \pm 0.08^{\mathrm{b}}$ & $72.02 \pm 0.59^{\mathrm{ab}}$ & $73.08 \pm 1.27^{\mathrm{a}}$ & $71.45 \pm 0.06^{\mathrm{b}}$ \\
\hline MUFA (relative \%) & $25.84 \pm 0.34^{\mathrm{a}}$ & $23.31 \pm 1.14^{\mathrm{b}}$ & $24.89 \pm 0.03^{\mathrm{a}}$ & $24.39 \pm 0.53^{\mathrm{ab}}$ & $23.29 \pm 1.25^{\mathrm{b}}$ & $24.97 \pm 0.08^{\mathrm{a}}$ \\
\hline PUFA (relative \%) & $3.52 \pm 0.08^{\mathrm{a}}$ & $3.58 \pm 0.07^{\mathrm{a}}$ & $3.56 \pm 0.04^{\mathrm{a}}$ & $3.59 \pm 0.07^{\mathrm{a}}$ & $3.63 \pm 0.01^{\mathrm{a}}$ & $3.57 \pm 0.03^{a}$ \\
\hline
\end{tabular}

$L^{*}, a^{*}$ and $b^{*}$ represent colour parameters; $C^{*}$ and $h^{\circ}$ correspond to the chroma and hue angle, respectively. Butyric acid (C4:0), caproic acid (C6:0); caprylic acid (C8:0); capric acid (C10:0); lauric acid (C12:0); myristic acid (C14:0); palmitic acid (C16:0); stearic acid (C18:0); oleic acid (C18:1n9); SFA-saturated fatty acids; MUFA-monounsaturated fatty acids; PUFA-polyunsaturated fatty acids. The difference to $100 \%$ corresponds to 13 other less abundant fatty acids (data not shown). In each line and for each storage time, different letters mean statistically significant differences $(p<0.05)$. 
concentrations of carbohydrates, higher than the cottage cheese added with the free extract. Lactose was the free sugar identified and quantified and decreased along time. The lactose values were significantly different in different samples, finding the highest levels in the control cheese at both days 0 and 7.

The energy revealed the same behavior at both times of analysis $\left(t_{0}\right.$ and $\left.t_{7}\right)$. The control cheese and the one with microspheres gave similar values, although the sample with the free extract showed lower energy values. As expected, the caloric values expressed in $100 \mathrm{~g}$ of fresh samples were higher after 7 days of storage, due to the decrease in moisture and the consequent increase in the concentration of nutrients.

In general, and despite the previously discussed changes, the values obtained for the various parameters are of the same magnitude in all sample groups. Moreover, the introduction of free and encapsulated extracts did not affect the nutritional value of the cottage cheese when compared with the control sample. Similar work with cottage cheese revealed identical values for colour and nutritional parameters. ${ }^{23,40}$

\section{Conclusion}

In this work, aqueous and hydroethanolic extracts of rosemary were compared regarding the phenolic composition, with aqueous extracts having a higher content and, consequently, a higher antioxidant activity. For this reason aqueous extracts were chosen to functionalize cottage cheeses. As expected, the incorporation of the extract in free form increased the antioxidant properties of the cheese, although it decreased after the storage time ( 7 days). Therefore, in order to preserve the antioxidant activity, the rosemary aqueous extract (after being lyophilized) was microencapsulated by using an atomization/ coagulation technique with an estimated encapsulation efficiency of around $100 \%$. Comparatively with control samples (cheese with no added extract), the nutritional value of cottage cheese was not affected by the introduction of the extract in free and microencapsulated forms. The samples added with the microencapsulated extracts maintained their antioxidant properties more efficiently throughout storage thus increasing the bioavailability upon ingestion.

\section{Acknowledgements}

The authors thank FCT for financial support to CIMO (Project PEst-OE/AGR/UI0690/2014), FCT/MEC and FEDER under Program PT2020 for financial support to LSRE (Project UID/ EQU/50020/2013), QREN, ON2 and FEDER (NORTE-07-0124FEDER-000014), and PRODER (Project no 46577-PlantLact). The GIP-USAL is financially supported by the Spanish Government through the Consolider-Ingenio 2010 Programme (FUN-C-FOOD, CSD2007-00063). L. Barros and C. Caleja thank FCT, POPH-QREN and FSE for their contracts ("Programa Compromisso com Ciência-2008” and SFRH/BD/93007/2013, respectively). The authors also thank Cantinho das Aromáticas Lda. for providing rosemary samples, and Queijos Casa Matias for the preparation of the cottage cheese samples.

\section{References}

1 M. Bellumori, M. Michelozzi, M. Innocenti, F. Congiu, G. Cencetti and N. Mulinacci, An innovative approach to the recovery of phenolic compounds and volatile terpenes from the same fresh foliar sample of Rosmarinus officinalis L., Talanta, 2015, 131, 81-87.

2 D. R. Berdahl and J. McKeague, Rosemary and sage extracts as antioxidants for food preservation, in Handbook of Antioxidants for Food Preservation, ed. F. Shahidi, USA, 2015, pp. 177-217.

3 N. Erkan, G. Ayranci and E. Ayranci, Antioxidant activities of rosemary (Rosmarinus officinalis L.) extract, blackseed (Nigella sativa L.) essential oil, carnosic acid, rosmarinic acid and sesamol, Food Chem., 2008, 110, 76-82.

4 E. Arraz, J. Mes, H. J. Wichers, L. Jaime, J. A. Mendiola, G. Reglero and S. Santoyo, Anti-inflammatory activity of the basolateral fraction of Caco-2 cells exposed to a rosemary supercritical extract, J. Funct. Foods, 2013, 13, 384-390.

5 S. A. A. Laham and F. M. Fadel, Antibacterial efficacy of variety plants against the resistant streptococcus which cause clinical mastitis cows, AJPRHC, 2013, 5, 32-41.

6 A. Al-Attar and N. A. Shawush, Influence of olive and rosemary leaves extracts on chemically induced liver cirrhosis in male rats, Saudi J. Biol. Sci., 2015, 22, 157-163.

7 T. Bakiral, U. Bakirel, O. U. Keles, S. G. Ulgen and $\mathrm{H}$. Yardibi, In vivo assessment of antidiabetic and antioxidant activities of rosemary (Rosmarinus officinalis) in alloxan-diabetic rabbits, J. Ethnopharmacol., 2008, 116, 64-73.

8 R. Couto, E. C. Conceição, L. T. Chaul, M. S. Oliveira, S. F. Alves, K. R. Rezende, M. T. F. Bara and J. R. Paula, Validated HPLC-PDA method for rosmarinic acid quantification in rosemary, Lat. Am. J. Pharm., 2011, 30, 19511956.

9 I. Dias, I. C. F. R. Ferreira and M. F. Barreiro, Microencapsulation of bioactives for food applications, Food Funct., 2015, 6(4), 1035-1052.

10 S. Heleno, A. Martins, M. J. R. P. Queiroz and I. C. F. R. Ferreira, Bioactivity of phenolic acids: Metabolites versus parent compounds: A review, Food Chem., 2015, 173, 501-513.

11 V. Nedovic, A. Kalusevic, V. Manojlovic, S. Levic and B. Bugarski, An overview of encapsulation technologies for food applications, Procedia Food Sci., 2011, 1, 1806-1815.

$12 \mathrm{H}$. Kwak, Overview of Nano-and Microencapsulation for Foods, in Nano- and Microencapsulation for Foods, ed. H.-S. Kwak, South Korea, 2014, pp. 1-14.

13 C. H. Goh, P. W. S. Heng and L. W. Chan, Alginates as a useful natural polymer for microencapsulation and therapeutic applications, Carbohydr. Polym., 2012, 88, 1-12. 
14 K. Y. Lee and D. J. Mooney, Alginate: properties and biomedical applications, Prog. Polym. Sci., 2012, 37, 106-126.

15 M. George and T. E. Abraham, Polyionic hydrocolloids for the intestinal delivery of protein drugs: Alginate and chitosan - a review, J. Controlled Release, 2006, 114, 1-14.

16 A. Martins, L. Barros, A. Carvalho, C. Santos-Buelga, I. Fernandes, M. F. Barreiro and I. C. Ferreira, Phenolic extracts of Rubus ulmifolius schott flowers: characterization, microencapsulation and incorporation into yogurts as nutraceutical sources, Food Funct., 2014, 5, 1091-1100.

17 I. Dias, L. Barros, I. Fernandes, G. Ruphuy, M. B. P. P. Oliveira, C. Santos-Buelga, M. F. Barreiro and I. C. F. R. Ferreira, A nutraceuticals formulations based on Fragaria vesca L. vegetative parts: characterization of the bioactives and application in k-carrageenan gelatin, J. Funct. Foods, 2015, 16, 243-255.

18 R. Stojanovic, A. Belscak-Cvitanovic, V. Manojlovic, D. Komes, V. Nedovic and B. Bugarski, Encapsulation of thyme (Thymus serpyllum L.) aqueous extract in calcium alginate beads, J. Sci. Food Agric., 2012, 92(3), 685-696.

19 D. Handley, M. Ma-Edmonds, F. Hamouz, S. Cuppett, R. Mandigo and M. Schnepf, Controlling oxidation and warmed-over flavor in precooked pork chops with rosemary oleoresin and edible film, in Natural antioxidants chemistry, health effect, and application, ed. F. Shahidi, AOCS Press, Champaign, USA, 1996, pp. 311-318.

20 M. Ma-Edmonds, F. Hamouz, S. Cuppett, R. Mandigo and S. M, Use of rosemary oleoresin and edible film to control warmed-over flavor in precooked beef patties, in IFT Annual Meeting Book of Abstracts, Institute of Food Technologists, Chicago, Illinois, 1995, p. 139.

21 L. Barros, E. Pereira, R. C. Calhelha, M. Dueñas, A. M. Carvalho, C. Santos-Buelga and I. C. F. R. Ferreira, Bioactivity and chemical characterization in hydrophilic and lipophilic compounds of Chenopolium ambrosioides L., J. Funct. Foods, 2013, 5, 1732-1740.

22 E. Pereira, L. Barros, R. C. Calhelha, M. Dueñas, A. M. Carvalho, C. Santos-Buelga and I. C. F. R. Ferreira, Bioactivity and phytochemical characterization of Arenaria montana L., Food Funct., 2014, 5, 1848-1855.

23 C. Caleja, L. Barros, A. L. Antonio, A. Ciric, M. Sokovic, M. B. P. P. Oliveira, C. Santos-Buelga and I. C. F. R. Ferreira, Foeniculum vulgare Mill. As natural conservation enhancer and health promoter by incorporation in cottage cheese, J. Funct. Foods, 2015, 12, 428-438.

24 M. Carocho, J. C. M. Barreira, A. L. Antonio, A. Bento, P. Morales and I. C. F. R. Ferreira, The incorporation of plant materials in "Serra da Estrela" cheese improves antioxidant activity without changing the fatty acid profile and visual appearance, Eur. J. Lipid Sci. Technol., 2015, 117, 1607-1614.

25 AOAC, in Official methods of analysis of AOAC international, ed. W. Horwitz and G. Latimer, AOAC International, Gaithersburg, MD, 18th edn, 2005.

26 I. Borrás-Linares, D. Arráez-Román, M. Herrero, E. Ibáñez, A. Segura-Carretero and A. Fernández-Gutiérrez, Compari- son of different extraction procedures for the comprehensive characterization of bioactive phenolic compounds in Rosmarinus officinalis by reversed-phase high-performance liquid chromatography with diode array detection coupled to electrospray time-of-flight mass spectrometry, J. Chromatogr., A, 2011, 1218, 7682-7690.

27 N. Mulinacci, M. Innocenti, C. Giaccherini, V. Martini and M. Michelozzi, Storage method, drying processes and extraction procedures strongly affect the phenolic fraction of rosemary leaves: An HPLC/DAD/MS study, Talanta, 2011, 85, 167-176.

28 I. Borrás-Linares, Z. Stojanović, R. Quirantes-Piné, D. Arráez-Román, J. Švarc-Gajić, A. Fernández-Gutiérrez and A. Segura-Carretero, Rosmarinus Officinalis Leaves as a Natural Source of Bioactive Compounds, Int. J. Mol. Sci., 2014, 14, 20585-20606.

29 P. P. Ferrer-Gallego, R. Ferrer-Gallego, R. Roselló, J. B. Peris, A. Guillén, J. Gómez and E. Laguna, A new subspecies of Rosmarinus officinalis (Lamiaceae) from the eastern sector of the Iberian Peninsula, Phytotaxa, 2014, 172, 61-70.

30 L. Maringer, E. Ibáñez, W. Bucherger, C. W. Klampfl and T. J. Causon, Using sheath-liquid reagents for capillary electrophoresis-mass spectrometry: Application to the analysis of phenolic plant extracts, Electrophoresis, 2015, 36, 348-354.

31 M. N. Clifford, K. L. Johnston, S. Knight and N. A. Kuhnert, A hierarchical scheme for LC-MSn identification of chlorogenic acids, J. Agric. Food Chem., 2003, 51, 2900-2911.

32 H. Chen, Q. Zhang, X. Wang, J. Yang and Q. Qang, Qualitative analysis and simultaneous quantification of phenolic compounds in the aerial parts of Salvia miltiorrhiza by HPLCDAD and ESI/MS ${ }^{n}$, Phytochem. Anal., 2011, 22, 247-257.

33 M. Ruan, Y. Li, X. Li, J. Luo and L. Kong, Qualitative and quantitative analysis of the major constituents on Chinese medicinal preparation Guan-Xin-Ning injection by HPLC-DAD-ESI-MS ${ }^{\mathrm{n}}$, J. Pharm. Biomed. Anal., 2012, 59, 184189.

34 L. Barros, M. Dueñas, M. I. Dias, M. J. Sousa, C. SantosBuelga and I. C. F. R. Ferreira, Phenolic profile of cultivated, in vitro cultured and commercial samples of Melissa officinalis L. infusions, Food Chem., 2013, 136, 1-8.

35 Y. Lu, L. Y. Foo and H. Wong, Sagecoumarin, a novel caffeic acid trimer from Salvia officinalis, Phytochemistry, 1999, 52, 1149-1152.

36 B. F. Zimmermann, S. G. Walch, L. N. Tinzoh, W. Stühlinger and D. W. Lachenmeier, Rapid UHPLC determination of polyphenols in aqueous infusions of Salvia officinalis L. (sage tea), J. Chromatogr., B: Biomed. Appl., 2011, 879, 2459-2464.

37 G. Zeng, H. Xiao, J. Liu and X. Liang, Identification of phenolic constituents in Radix Salvia miltiorrhizae by liquid chromatography/electrospray ionization mass spectrometry, Rapid Commun. Mass Spectrom., 2006, 20, 499-506.

38 Z. Zhu, H. Zhang, L. Zhao, X. Dong, X. Li, Y. Chai and G. Zhang, Rapid separation and identification of phenolic 
and diterpenoid constituents from Radix Salvia miltiorrhizae by high-performance liquid chromatography diodearray detection, electrospray ionization time-of-flight mass spectrometry and electrospray ionization quadrupole ion trap mass spectrometry, Rapid Commun. Mass Spectrom., 2007, 21, 1855-1865.

39 C. Yu, B. Yina, W. Zhanga, S. Chenga, X. Zhanga and R. Zhuoa, Composite microparticle drug delivery systems based on chitosan, alginate and pectin with improved $\mathrm{pH}$ sensitive drug release property, Colloids Surf., B, 2009, 68, 245-249.

40 A. Ribeiro, G. Ruphuy, J. C. Lopes, M. M. Dias, L. Barros, F. Barreiro and I. C. F. R. Ferreira, Spray-drying microencapsulation of synergistic antioxidant mushroom extracts and their use as functional food ingredients, Food Chem., 2015, 188, 612-618. 